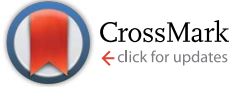

Cite this: RSC Adv., 2017, 7, 2621

Received 4th October 2016

Accepted 18th November 2016

DOI: 10.1039/c6ra24719a

www.rsc.org/advances

\section{Hydrophilic PAN based carbon nanofibres with improved graphitic structure and enhanced mechanical performance using ethylenediamine functionalized graphene $\uparrow$}

\author{
Zhenyu Li, Omid Zabihi, Jinfeng Wang, Quanxiang Li, Jiemin Wang, Weiwei Lei \\ and Minoo Naebe*
}

Polyacrylonitrile (PAN) reinforced with nano-carbons such as graphene (Gr) and carbon nanotubes (CNTs) provides great opportunity for the development of low-cost and high-performance carbon materials. However, the poor dispersion and weak interaction between the carbon nanofillers and the surrounding PAN matrix prevent the final carbonized materials from reaching their full potential. Herein, we demonstrate a chemical approach using ethylenediamine (EDA) acting as a linker between graphene nanoplatelets and PAN for improved mechanical performance. The as-prepared CNFs exhibit a higher carbon yield and tensile modulus as well as improved graphitic structure compared to pristine PAN and PAN/Gr nanofibres. Furthermore, EDA can act as a $\mathrm{N}$ source for $\mathrm{N}$-doping during the carbonization, enabling CNFs with hydrophilicity performance.

\section{Introduction}

Continuous carbon nanofibres (CNFs) derived from carbonized electrospun polymeric precursor nanofibres have received much attention in diverse fields such as catalysis, ${ }^{1}$ sensor, ${ }^{2}$ absorption/separation, ${ }^{3}$ and biomedical applications, ${ }^{4}$ driven by their high surface area, robust mechanical properties, excellent chemical resistance, and outstanding electrical/thermal conductivity. ${ }^{5}$ Among various polymeric precursors, polyacrylonitrile (PAN) is well-known to produce CNFs with fairly high carbon yield and tensile strength. ${ }^{6}$ However, most of the obtained CNFs still suffer a relatively low tensile modulus and modest electrical/thermal conductivity owing to the imperfection of the graphitic structure during the carbonization.

The conventional method to improve the graphitic structures of carbon fibres is to increase the carbonization temperature, ${ }^{7,8}$ which requires specialized and expensive equipment, leading to high energy consumption and cost. ${ }^{9}$ Therefore, lowcost approaches for carbon fibres with improved graphitic structures and enhanced mechanical performance at relatively low carbonization temperature are of much interest. Nanocarbons such as carbon nanotubes $(\mathrm{CNTs}),{ }^{10}$ graphene oxide

Institute for Frontier Materials, Deakin University, Victoria 3216, Australia. E-mail: minoo.naebe@deakin.edu.au; Tel: +61403667708

$\dagger$ Electronic supplementary information (ESI) available: TEM, Raman spectra, FTIR spectra and TGA curves of the Gr and Gr-EDA compound, FTIR spectra of the PAN and PAN@EDA@Gr samples, Raman spectra and computer decompositions of the derived CFs with different carbonized temperatures. See DOI: $10.1039 /$ c6ra24719a
(GO) ${ }^{11}$ and graphene $(\mathrm{Gr}){ }^{12}$ possess exceptional mechanical, electrical, thermal, and optical performances, making them appealing for the development of high performance composites and fibres. ${ }^{13,14}$ Taking the advantages of large surface area and long range graphitic structure, large interfacial area will be created between the carbon nanofillers and surrounding polymeric matrix. At this stage, the polymer chains around carbon nanofillers can be re-organized for several radii of gyration ${ }^{15}$ leading to improved graphitic structures during the carbonization. ${ }^{16}$ It has been shown that the graphitic structure of CNFs can be greatly improved at relative low carbonized temperature with the addition of low volume fractions of $\mathrm{Gr}$ or double wall carbon nanotubes. ${ }^{17}$ However, the dispersion of the nanofillers within the surrounding polymeric matrix is still quite poor due to the weak interactions between nanofiller and matrix, resulting in modest graphitic structure within the final CNFs. Although the dispersion of the carbon nanofillers can be greatly improved by surface oxidization, the intrinsic high oxygen contents of oxidized carbon nanofillers will lead to high weight loss during the carbonization, inhibiting their applications in fabricating CNFs with high carbon yield.

Ethylenediamine (EDA) has obtained particular attention in modifying carbon nanomaterials such as hydrogenated fullerenes, ${ }^{18}$ carbon nanotubes, ${ }^{19}$ and graphene ${ }^{20}$ via Benkeser hydrogenation. In the case of PAN matrix, the amine groups of EDA can also react with nitrile group of PAN to form the amineterminated polymers. ${ }^{21}$ Thus the two amine groups on both sides of the ethylene can act as a linker between carbon nanofiller and PAN nitrile group. Prompted by such appealing 
performance of EDA, in this study, we demonstrated an effective approach to improve the dispersion and interaction between carbon nanofillers and PAN matrix using EDA. Our results show that the derived CNFs exhibited enhanced mechanical performance and graphitic order at relatively low carbonized temperature in contrast to those derived from PAN nanofibres and PAN/Gr composite nanofibres. What's more, EDA can also act as $\mathrm{N}$ source for $\mathrm{N}$-doping during the carbonization, surprisingly changing the surface wettability.

\section{Experimental section}

\subsection{Materials}

Polyacrylonitrile (PAN: Mw 150000 , Sigma-Aldrich) and $N, N$ dimethyl formamide (DMF, Sigma-Aldrich) were used as received. Ethylenediamine (EDA, Sigma-Aldrich) was dried by $\mathrm{KOH}$ (Sigma-Aldrich) for $24 \mathrm{~h}$ before use. Graphene nanoplatelet (grade $\mathrm{C}$, surface area of $\sim 518 \mathrm{~m}^{2} \mathrm{~g}^{-1}$ as measured by BET) was supplied XG Sciences (Michigan, USA). Lithium chip (MTI) was stored in glove box under Ar atmosphere prior to use.

\subsection{Synthesis of Gr@EDA}

Three lithium chips ( $\sim 99 \mathrm{mg}$ ) were dissolved in $80 \mathrm{~mL}$ of dry ethylenediamine (EDA), in a nitrogen-purged four-necked round-bottomed flask $(250 \mathrm{~mL})$ with vigorous stirring, at room temperature for $\sim 4 \mathrm{~h}$. Then, $80 \mathrm{mg}$ of $\mathrm{Gr}$ was added into the solution under vigorous stirring and nitrogen purge. After $24 \mathrm{~h}$ at $50{ }^{\circ} \mathrm{C}$, the solution was quenched by bubbling air for $1 \mathrm{~h}$. The suspension was filtered using a $0.2 \mu \mathrm{m}$ polycarbonate membrane and washed with copious acetone, ethanol, distilled water, and acetone in turn. Gr@EDA samples were then kept in vacuum oven at $50{ }^{\circ} \mathrm{C}$ for 3 days before use.

\subsection{Grafting of Gr@EDA on PAN for FTIR-ATR measurement}

In a typical process, $0.1 \mathrm{~g}$ of PAN was added into $20 \mathrm{~mL}$ of DMF in flask $(100 \mathrm{~mL})$. The solution was kept at $90{ }^{\circ} \mathrm{C}$ for $12 \mathrm{~h}$ under vigorous stirring and cooled down to room temperature. $0.1 \mathrm{~g}$ of Gr-EDA was added into $20 \mathrm{~mL}$ of DMF and sonicated for $3 \mathrm{~h}$. Then the Gr-EDA/DMF solution was added into the PAN/DMF solution and stirred for $6 \mathrm{~h}$, followed by heating to $70{ }^{\circ} \mathrm{C}$ for $24 \mathrm{~h}$ under vigorous stirring. At this stage, Gr@EDA will be grafted onto PAN. The PAN@Gr@EDA sample was obtained by dropping the PAN@Gr@EDA solution into an acetone coagulation bath through wet-spinning method. Acetone was used to rinse the samples for three times. Before the FTIR measurement, the Gr-EDA-PAN sample was kept in vacuum oven at $50{ }^{\circ} \mathrm{C}$ for $3 \mathrm{~d}$.

\subsection{Preparation of the PAN@Gr@EDA and PAN/Gr solution for electrospinning}

In a typical process, $1.1 \mathrm{~g}$ of PAN was added into $9 \mathrm{~mL}$ of DMF in vial $(20 \mathrm{~mL})$. The solution was then kept at $90{ }^{\circ} \mathrm{C}$ for $12 \mathrm{~h}$ under vigorous stirring and cooled down to room temperature. Gr@EDA ( $1 \mathrm{wt} \%$ respect to the PAN) was added into $1 \mathrm{~mL}$ of DMF and sonicated (Unisonics, Australia) for $3 \mathrm{~h}$ before adding it into the PAN/DMF solution. The resulting solution was stirred for $72 \mathrm{~h}$ in which the solution was sonicated for $6 \mathrm{~h}$ to disperse the Gr@EDA within PAN matrix. Then, the solution was heated up to $70{ }^{\circ} \mathrm{C}$ for $24 \mathrm{~h}$ under vigorous stirring to graft Gr@EDA on PAN. Gr/PAN sample was also prepared following the same protocol using 11\% PAN/DMF solution containing 1\% Gr.

\subsection{Electrospinning process}

Electrospinning was conducted in air with the relative humidity $(30-40 \%)$ with a set up described previously. ${ }^{22}$ The spinning solutions were loaded into a plastic syringe (23 gauge needle). The flow rate was fixed at $0.6 \mathrm{~mL} \mathrm{~h}^{-1}$ by a syringe pump (KDS $200, \mathrm{KD}$ Scientific Inc.). A high-voltage $(20 \mathrm{kV})$ and a grounded rotating drum was used (surface linear speed $12.8 \mathrm{~m} \mathrm{~s}^{-1}$ ). The distance between the tip and the collector was $21 \mathrm{~cm}$.

\subsection{Thermal stabilisation and carbonization}

The aligned nanofibre mats were heated to $250{ }^{\circ} \mathrm{C}$ from room temperature with the heating rate of $3{ }^{\circ} \mathrm{C} \mathrm{min}{ }^{-1}$ and kept for $2 \mathrm{~h}$ in air for thermal stabilisation. Consequently, the oxidised nanofibre mats were taken out of the oven and cooled down to the room temperature in air. The stabilised nanofiber mats were carbonised under $\mathrm{N}_{2}$ atmosphere using a tube furnace. Samples were heated to $650{ }^{\circ} \mathrm{C}$ or $850{ }^{\circ} \mathrm{C}\left(2{ }^{\circ} \mathrm{C} \mathrm{min}{ }^{-1}\right)$ and dwell for $2 \mathrm{~h}$.

\subsection{Characterization}

TEM and SEM images were taken on a JEOL-2100 TEM with an acceleration voltage of $200 \mathrm{kV}$ and a Supra 55VP SEM, respectively. X-ray diffraction was carried out with a Scintag XDS 2000 diffractometer with $\mathrm{Cu} \mathrm{K} \alpha$ radiation. FTIR-ATR was performed using a Bruker Vertex 70 FTIR spectrometer in ATR mode with a resolution of $4 \mathrm{~cm}^{-1}$. Raman was used to characterize the graphitic structure of the carbonized samples via inVia Raman microscope from Renishaw with $514 \mathrm{~nm}$ laser as an excitation source. Tensile test was carried out using a Favimat instrument (Textechno, Monchengladbach, Germany). The gauge length for testing was fixed at $1 \mathrm{~cm}$ and the strain rate was $1.0 \mathrm{~mm} \mathrm{~min}{ }^{-1}$. Thermogravimetric analyses (TGA) were carried out on a Pyris-1 thermogravimetric analyzer (Perkin Elmer, USA) with a heating rate of $10^{\circ} \mathrm{C} \mathrm{min}^{-1}$ under air or $\mathrm{N}_{2}$ atmosphere. Rheometer test was performed using a TA DHR 3 rheometer with cone-plate geometry at $25{ }^{\circ} \mathrm{C}$. A cone with a diameter of $40 \mathrm{~mm}$ and a tilt angle of $2^{\circ}$ was used, and gap width was set to be $50 \mu \mathrm{m}$. The solutions were placed between the cone and plate and were soaked for five minutes before testing. The contact angles were measured using a contact angle goniometer (KSV CAM 101). The water drop for the test was $5 \mathrm{~mL}$ in volume. X-ray photoelectron spectra (XPS) were recorded on an ESCLAB MKII using $\mathrm{Al}$ as the excitation source.

\section{Results and discussion}

Benkeser hydrogenation process has been selected to graft EDA on graphene nanoplatelets, ${ }^{20,23}$ in which the lithium reacts with EDA firstly and generates the monolithium amid derivative ( $\mathrm{Li}-$ EDA). Then Li-EDA will attack the $\mathrm{C}=\mathrm{C}$ of $\mathrm{Gr}$ to form the EDA covalently bonded graphene (EDA@Gr). TEM, Raman and FTIR 


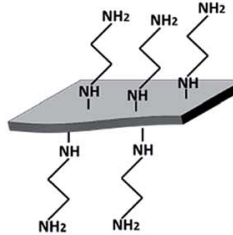

$+\underbrace{}_{C \equiv N} \underbrace{}_{C \equiv N}$<smiles>CC1(C)CCC1CC(C#N)CC1C=NCC1</smiles>
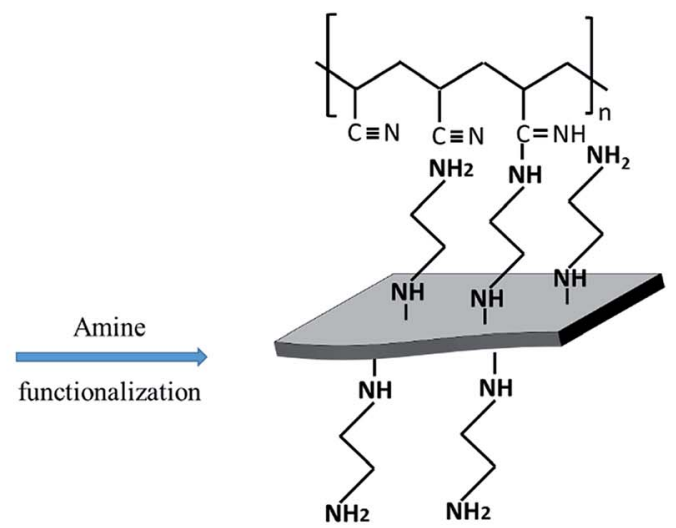

Scheme 1 Mechanism of bonding between functionalised Gr and PAN

have been used to characterize the Gr and EDA@Gr (see ESI Fig. S1-S3†). From the TEM images (Fig. S1†), it can be seen that the overlap phenomenon of Gr diminished after EDA grafting, confirming that EDA grafting can improve the dispersion within ethanol solvent. From the Raman spectra (Fig. S2 $\dagger$ ), the reduced $I_{\mathrm{D}} / I_{\mathrm{G}}$ ratio confirms destruction of the $\mathrm{sp}^{2}$ character and formation of the defects in commercial graphene nanoplatelets after EDA grafting. FTIR spectra (Fig. S3†) demonstrate two new and weak peaks at $2920 \mathrm{~cm}^{-1}$ and $2855 \mathrm{~cm}^{-1}$ corresponding to the typical $\mathrm{C}\left(\mathrm{sp}^{3}\right)-\mathrm{H}$ stretching vibration, which is consistent with the previous studies. ${ }^{23}$ In addition, the presence of strong $\mathrm{C}-\mathrm{C}$ stretching bands $\left(1200 \mathrm{~cm}^{-1}\right)$ and $\mathrm{C}-\mathrm{N}$ stretching bands $\left(1150 \mathrm{~cm}^{-1}\right)$, confirm the presence of EDA on Gr. The chemical functionalization of $\mathrm{Gr}$ was further confirmed by TGA analysis (ESI Fig. S4 †). A difference of $\sim 13 \%$ weight loss between pure $\mathrm{Gr}$ and EDA@Gr at $600{ }^{\circ} \mathrm{C}$ shows the thermal decomposition of EDA, confirming the presence of EDA on graphene nanoplatelets.

The chemical bonds between EDA@Gr and PAN to form PAN@EDA@Gr has been confirmed by FTIR (ESI Fig. S4 †). Before grafting, the characteristics bands of PAN at $2243 \mathrm{~cm}^{-1}$ and $1450 \mathrm{~cm}^{-1}$ corresponding to $\mathrm{CN}$ and $\mathrm{CH}$ vibrating bands can be seen. The peak observed at $2939 \mathrm{~cm}^{-1}$ can be assigned to $\mathrm{CH}$ stretching for PAN. Additionally, the characteristic peak of $\mathrm{C}=\mathrm{O}$ stretching of DMF at $1660 \mathrm{~cm}^{-1}$ (ref. 24) is observed. After grafting, a new peak at $1595 \mathrm{~cm}^{-1}$ corresponding to the $\mathrm{C}=\mathrm{N}$ vibrating band appeared confirming the chemical bonds between nitrile group of PAN and the amine group of EDA. At this stage, the two amine groups on both sides of the ethylene can be regarded as a linker between $\mathrm{Gr}$ and PAN nitrile group, simultaneously (Scheme 1).

Fig. 1a-c present the typical SEM images of the electrospun PAN, PAN-Gr, and PAN@EDA@Gr nanofibres, respectively, indicating smooth PAN, PAN-Gr, and PAN-EDA-Gr fibres are produced via electrospinning route with the average diameter of $450 \pm 20 \mathrm{~nm}, 420 \pm 20 \mathrm{~nm}$, and $380 \pm 30 \mathrm{~nm}$, respectively. The thinner diameters of the PAN-Gr is due to lower viscosity of the spun solution as a result of Gr inclusion. In contrast to the PANGr, the diameter of PAN@EDA@Gr is thinner, implying the stronger interactions between PAN and Gr@EDA. To clearly see the distribution of Gr and Gr@EDA within the PAN fiber, TEM was used to characterize the samples (Fig. 1d-f). Different from

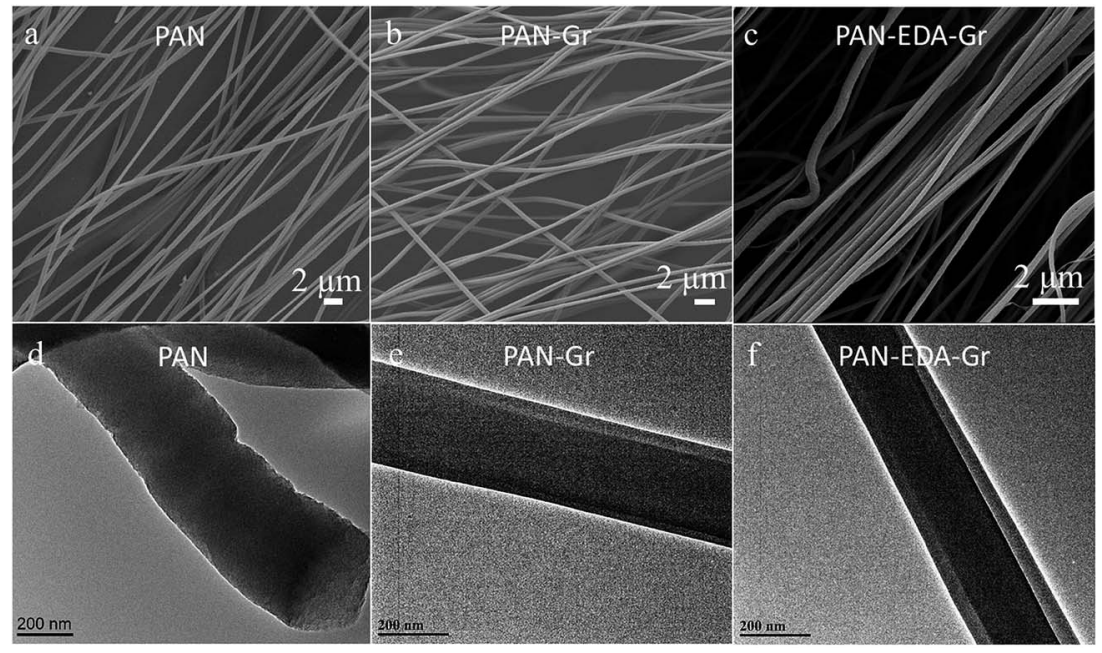

Fig. 1 SEM and TEM images of the ( $a$ and d) PAN, ( $b$ and e) PAN-Gr, and ( $c$ and f) PAN@EDA@Gr nanofibres, respectively. 


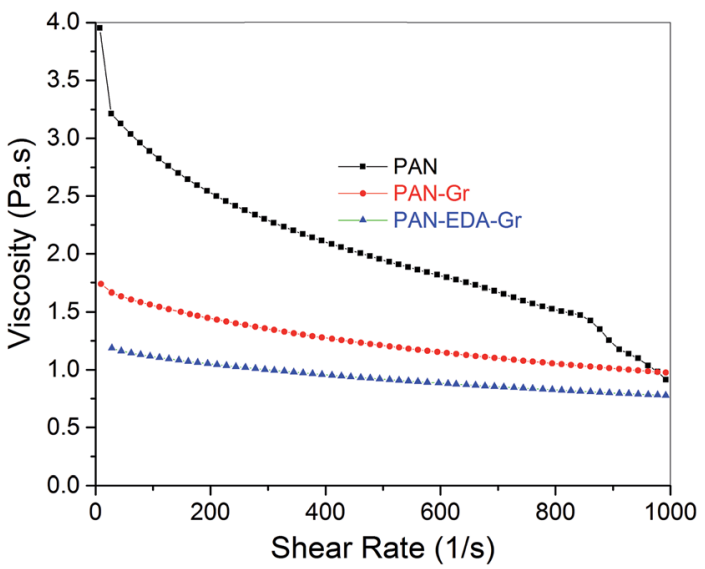

Fig. 2 Viscosity versus shear rate for PAN, PAN-Gr, and PANaEDA@Gr solutions in DMF solvent. Concentration of PAN/DMF in solutions was fixed at $1.1 \mathrm{~g} / 10 \mathrm{~mL}$.

PAN nanofibres, a darker core surrounded by a lighter skin structure can be detected from PAN-Gr and PAN@EDA@Gr nanofibres, confirming that Gr and EDA-Gr were incorporated inside the PAN fibres.

To better unveil the reason for smaller diameters of PAN-Gr and PAN@EDA@Gr, the viscosities of those three solutions have been measured as shown in Fig. 2, displaying that all solutions exhibit non-newtonian behaviours and that shear thinning phenomena is more conspicuous for pure PAN solution. Furthermore, the decrease in viscosity by adding Gr and EDA@Gr, means that more PAN chains have been absorbed on their surfaces, ${ }^{25}$ resulting in the less inter-entangled PAN chains within the solution and the weak shear thinning region at high shear force. The lowest viscosity of PAN@EDA@Gr in DMF solution, means the stronger interactions between PAN and EDA@Gr.

Fig. 3 shows the FTIR spectra in ATR mode of as-prepared nanofibres before and after stabilisation. Before the stabilisation, PAN distinct peaks at 2939, 2243, and $1454 \mathrm{~cm}^{-1}$ corresponding to $\mathrm{CH}$ stretching, $\mathrm{CN}$ and $\mathrm{CH}$ vibrating bands can be detected, respectively (Fig. 3a). After the stabilisation, a new peak at $1595 \mathrm{~cm}^{-1}$ assigned to conjugated $\mathrm{C}=\mathrm{N}$ stretching appeared due to the cyclization and dehydrogenation of the nanofiber, and the intensity of $\mathrm{CN}$ vibrating band $\left(2243 \mathrm{~cm}^{-1}\right)$ in stabilized nanofibres reduced. ${ }^{26}$ From Fig. 3b, the degree of stabilisation or extent of reaction $\left[\mathrm{EOR}=I_{1595} /\left(I_{1595}+I_{2242}\right)\right]$ can be quantified using the intensity of the peak at 1595 and 2243 $\mathrm{cm}^{-1}$, respectively. As expected, the PAN-Gr and PAN@EDA@Gr nanofibres exhibited higher EOR value of $\sim 0.94$ and $\sim 0.95$, respectively. But EOR of pristine PAN is only $\sim 0.92$ at $250{ }^{\circ} \mathrm{C}$ in air for $3 \mathrm{~h}$.

Morphologies of nanofiber samples under different carbonized temperature i.e. 650 and $850{ }^{\circ} \mathrm{C}$ have been observed using SEM as shown in Fig. 4. In contrast to their precursors, the diameters of CNFs reduced as the carbonized temperature increase. By increase in carbonization temperature from 650 to $850^{\circ} \mathrm{C}$, the diameters of fibres change from $380 \pm 30 \mathrm{~nm}$ to 330 $\pm 30 \mathrm{~nm}$, respectively. Same trend can be observed for CNFs derived from PAN-Gr and PAN@EDA@Gr as well.

The effect of adding Gr and Gr@EDA on carbon yield of PAN precursor has been evaluated via TGA, in which the carbon yield can be calculated as the weight loss value at $800{ }^{\circ} \mathrm{C}$ (Fig. 5a). From the TGA curves, the carbon yield for PAN, PAN-Gr, and PAN@EDA@Gr can be defined as 51\%,60\%, and 67\%, respectively. The high carbon yield of PAN-Gr and PAN@EDA@Gr derived CNFs lies in the barrier effect of Gr and Gr-EDA, which can effectively obstruct the diffusion of volatile products from the carbonized PAN nanofiber to the gas phase, therefore slowing down the decomposition process. The higher carbon yield of PAN@EDA@Gr compared to PAN-Gr confirms the stronger interaction between PAN and Gr@EDA than that of PAN-Gr composites. XRD analysis was conducted to better understand the influence of $\mathrm{Gr}$ and Gr@EDA on the evolution of the graphitic structure during carbonization. As the carbonized temperature was $650{ }^{\circ} \mathrm{C}$, no peaks could be observed for PAN fibres derived CNFs, whereas PAN-Gr and PAN@EDA@Gr derived CNFs exhibited strong (002) peak, confirming the enhanced graphitic structure (Fig. 5b). As the carbonized temperature is $850{ }^{\circ} \mathrm{C}$, one new (100) peak appeared, confirming further improvement in graphitic structure (Fig. 5c). Such enhanced graphitic structure lies in the nucleating effect of Gr and EDA@Gr during the carbonization. ${ }^{\mathbf{1 6}}$ To further support our data, Raman spectroscopy was employed and results are shown in Fig. 5d and e. Two apparent peaks at 1330 and 1585 $\mathrm{cm}^{-1}$, corresponding to the $\mathrm{D}$ band and $\mathrm{G}$ band, respectively, can be observed. The D-band represents the defects in carbon
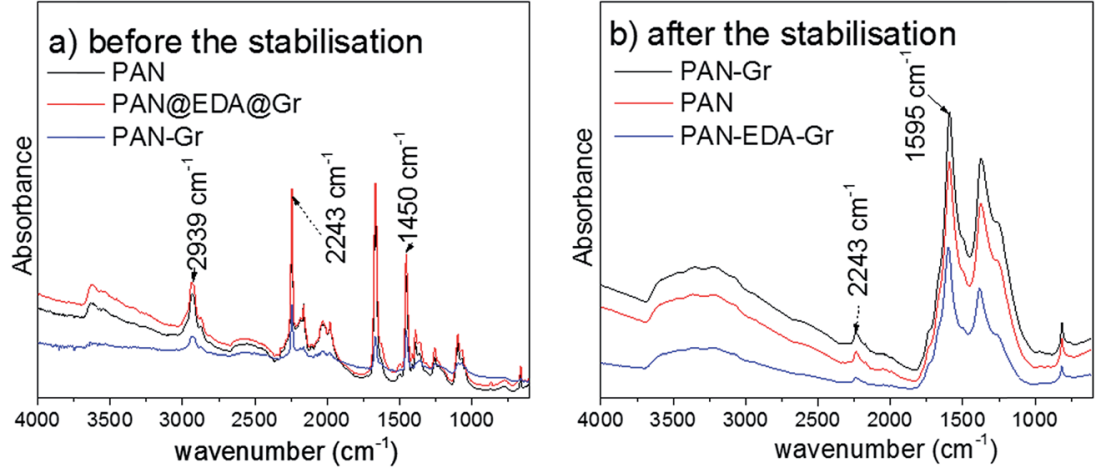

Fig. 3 ATR infrared spectra of as-prepared fibres before (a) and after (b) thermal stabilization at $250{ }^{\circ} \mathrm{C}$ in air for $3 \mathrm{~h}$. 


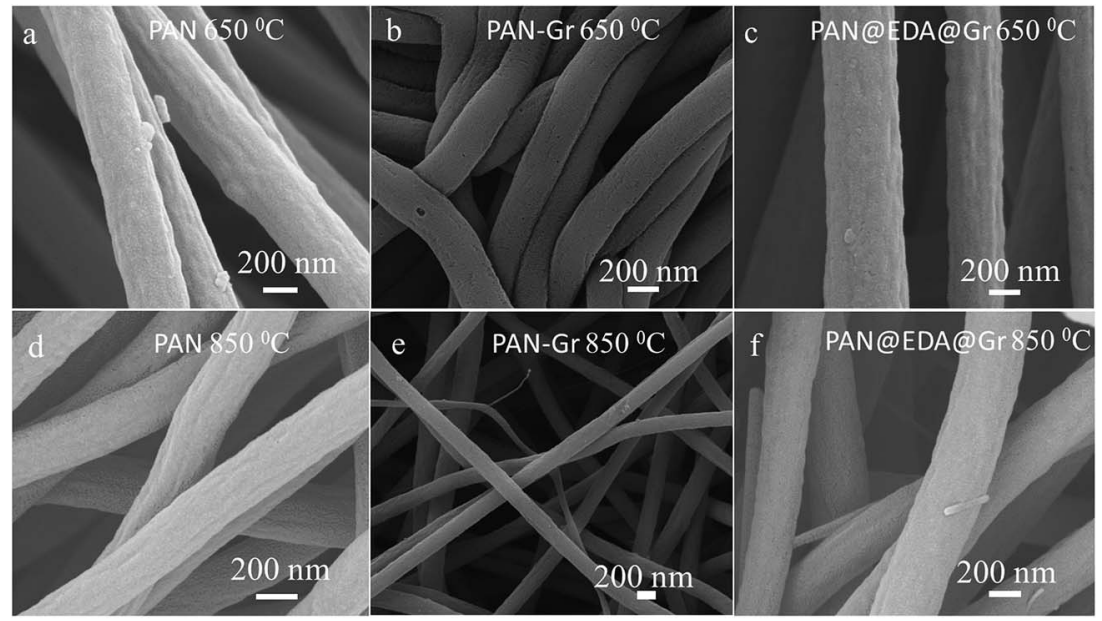

Fig. 4 SEM images of the CNFs at different carbonized temperature derived from PAN (a and d), PAN-Gr (b and e), and PAN@EDA@Gr (c and f) precursors.
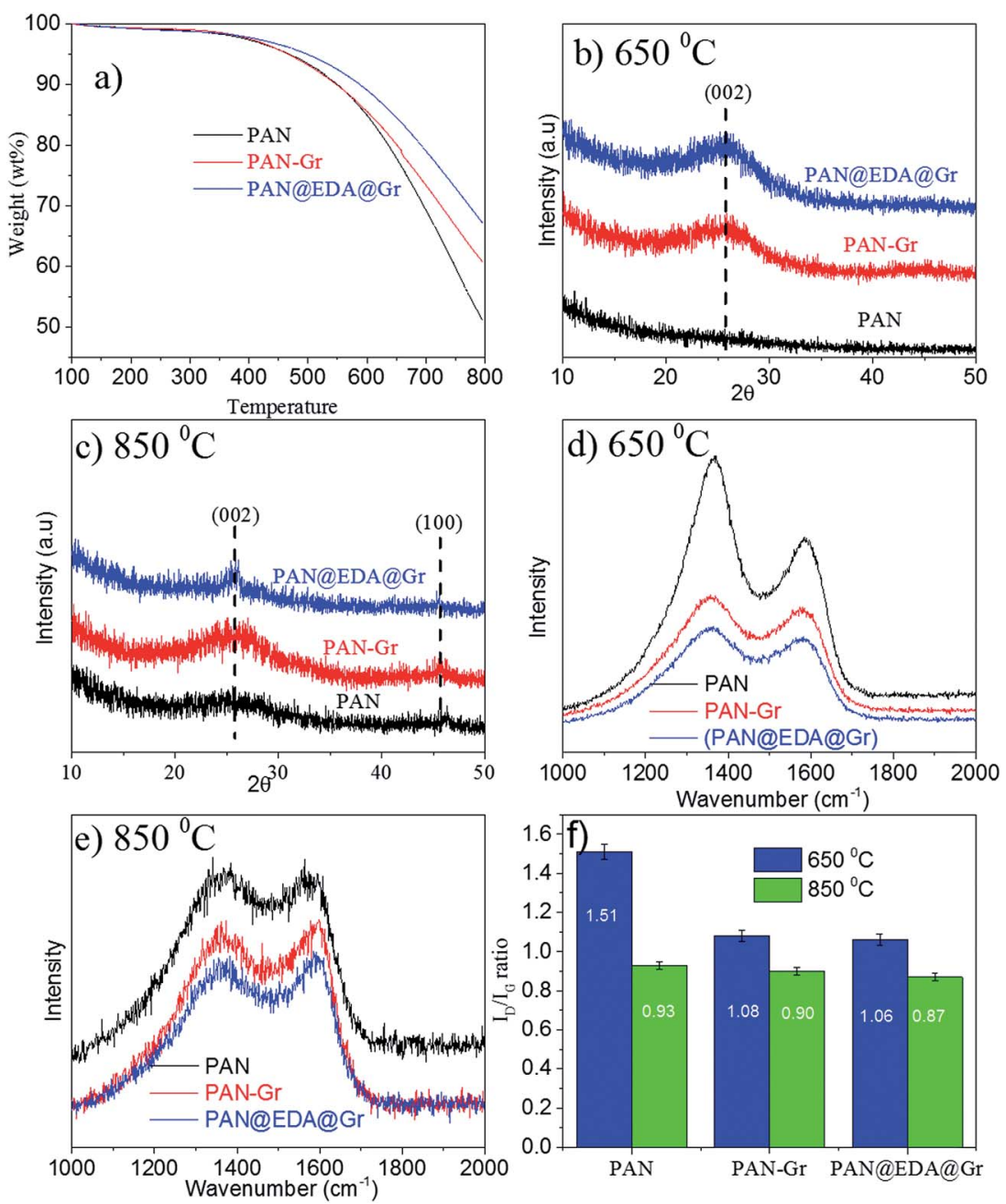

Fig. 5 (a) Carbon yield of PAN, PAN-Gr, and PAN@EDA@Gr derived CNFs at $800^{\circ} \mathrm{C}$, (b) and (c) are XRD of the samples carbonized at $650{ }^{\circ} \mathrm{C}$ and $850^{\circ} \mathrm{C}$, respectively, (d) and (e) are Raman spectra of samples carbonized at $650^{\circ} \mathrm{C}$ and $850{ }^{\circ} \mathrm{C}$, respectively, (f) is the calculated ratio of $I_{D} / I_{G}$ at different carbonized temperatures. 
Table 1 Young's modulus of PAN, PAN-Gr, and PAN-EDA-Gr fiber film carbonized at $650{ }^{\circ} \mathrm{C}$ and $850^{\circ} \mathrm{C}$

\begin{tabular}{lll}
\hline Samples & $\begin{array}{l}\text { Young's modulus } \\
\text { at } 650{ }^{\circ} \mathrm{C}(\mathrm{MPa})\end{array}$ & $\begin{array}{l}\text { Young's modulus } \\
\text { at } 850^{\circ} \mathrm{C}(\mathrm{MPa})\end{array}$ \\
\hline PAN derived CNFs & $200 \pm 20$ & $400 \pm 50$ \\
PAN-Gr derived CNFs & $250 \pm 30$ & $520 \pm 40$ \\
$\begin{array}{l}\text { PAN-Gr-EDA } \\
\text { derived CNFs }\end{array}$ & $400 \pm 20$ & $620 \pm 40$
\end{tabular}

structure, and the G-band is related to the $\mathrm{sp}^{2}$ carbon-carbon stretching vibrations ( $\mathrm{sp}^{2}$ carbon atoms) in graphite layers. ${ }^{27} \mathrm{It}$ can be clearly seen that the addition of Gr and EDA@Gr significantly improve the intensity of $\mathrm{G}$ band, which is consistent with the XRD data discussed above. The ratio $R=I_{\mathrm{D}} / I_{\mathrm{G}}$ was calculated by fitting the D and G peaks using Gaussian curves (ESI Fig. S6†) superimposed on a linear and results have been illustrated in Fig. 4f. The $I_{\mathrm{D}} / I_{\mathrm{G}}$ ratio for sample containing EDA@Gr is lower than those of pure PAN and PAN-Gr, indicating the higher graphitic structure at the same carbonization temperature.

The influence of Gr and Gr@EDA on the mechanical properties of the final CNFs were also investigated. The Young modulus of CNFs carbonised at 650 and $850^{\circ} \mathrm{C}$ are presented in

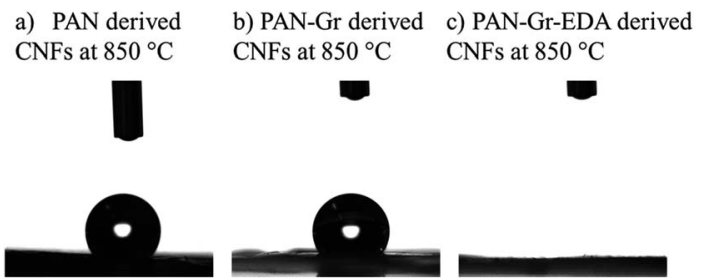

Fig. 7 Profiles of water contact angle on derived CNFs carbonized at $850^{\circ} \mathrm{C}$ derived from (a) pure PAN, (b) PAN-Gr, and (c) PAN@EDA@Gr.

Table 1 and the typical stress-stain $(S-S)$ curves are shown in Fig. 6. It is important to emphasize that our $S-S$ curves are not the straight line like other carbon materials ${ }^{28}$ owing to the not well alignment of the fibres within the film. Thus the Young's modulus was calculated by stress/strain when the straight line emerge. As the carbonized temperature is $650{ }^{\circ} \mathrm{C}$, the Young's modulus of CNFs derived from PAN, PAN-Gr and PAN@EDA@Gr were increased from $200 \pm 20 \mathrm{MPa}$, to $250 \pm 30 \mathrm{MPa}$, and to $400 \pm 20 \mathrm{MPa}$. While the Young's modulus for PAN-Gr and PAN@EDA@Gr derived CNFs at $850{ }^{\circ} \mathrm{C}$ can reach $520 \pm$ $40 \mathrm{MPa}$ and $620 \pm 40 \mathrm{MPa}$, respectively, which is $\sim 127 \%$ and $150 \%$ higher than that of PAN-derived CNFs. Such increase in
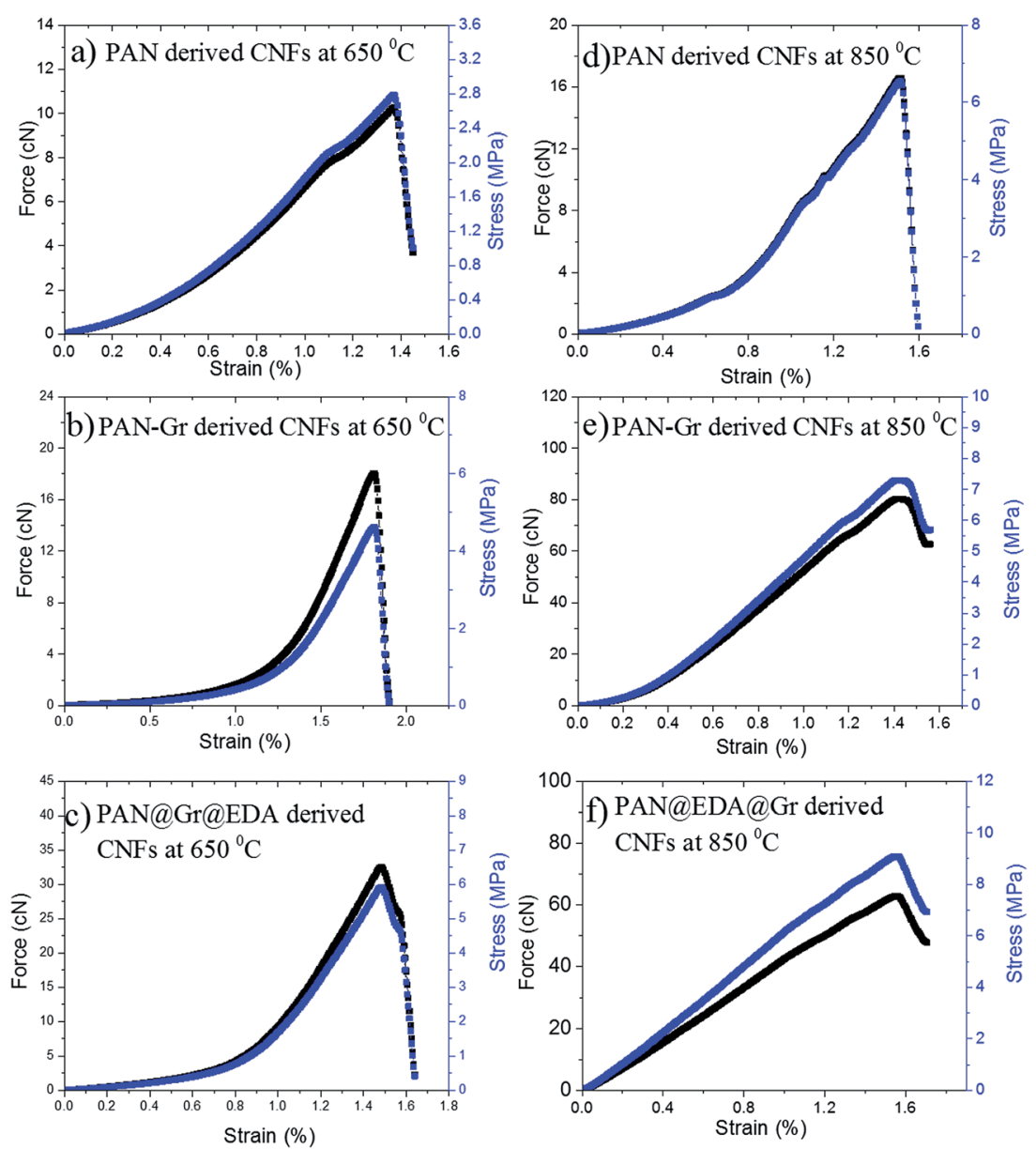

Fig. 6 Stress-stain (S-S) curves of PAN, PAN-Gr, and PAN@EDA@Gr derived CNFs at different carbonized temperatures. 

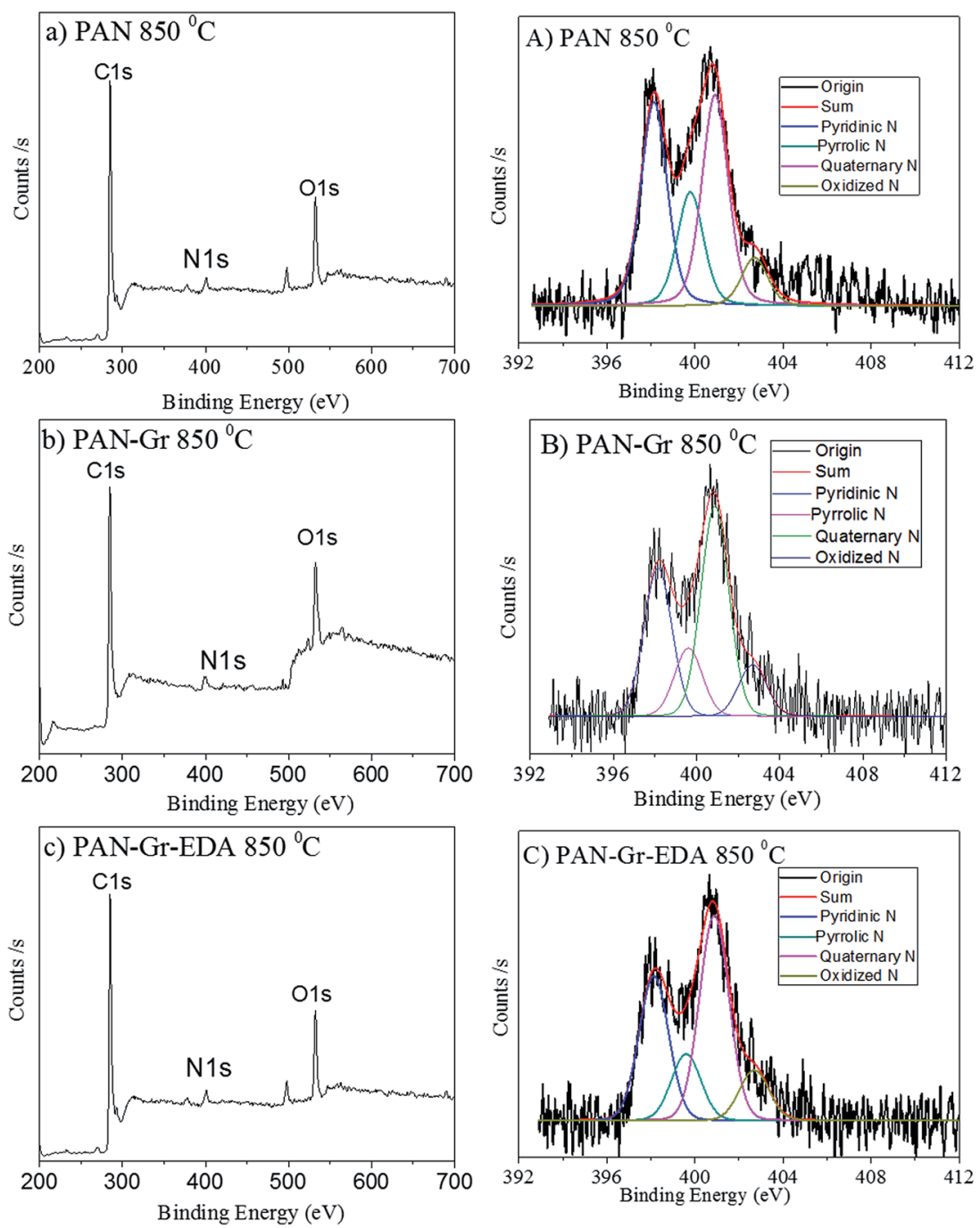

Fig. 8 XPS survey spectra of the samples $(a-c)$ and their corresponding N1s high resolution $(A-C)$.

the mechanical performances could be due to the reinforcing effect of $\mathrm{Gr}(\mathrm{EDA}-\mathrm{Gr})^{29}$ as well as reduced diameter of nanofibres. ${ }^{30}$ Comparing with PAN-Gr derived CNFs, PAN@EDA@Gr derived CNFs exhibit higher Young's modulus, assigned to the stronger interactions between PAN and Gr@EDA.

The effects of adding Gr and Gr@EDA nanofillers on the wettability of CNFs carbonized at $850{ }^{\circ} \mathrm{C}$ were also investigated using water contact angle (WCA) as shown in Fig. 7. For pure PAN derived CNFs, the WCA is $142.8 \pm 0.5^{\circ}$ (Fig. 7a). As for the PAN-Gr derived CNFs, the WCA decreased to $131.5 \pm 0.1^{\circ}$ (Fig. 7b). For PAN-Gr-EDA derived CNFs (Fig. 7c), a significant decrease to $0^{\circ}$ was observed, namely, hydrophilic CNFs have been obtained. Such phenomenon was ascribed to the $\mathrm{N}$-doping during the carbonization with the EDA acting as $\mathrm{N}$ source, which change the wettability of the final product. ${ }^{31}$ To further prove our hypothesis, X-ray photoelectron spectroscopy (XPS) has been used to analyse the element composition within the final samples sintered at $850{ }^{\circ} \mathrm{C}$ as shown in Fig. 8. From the survey spectra, three typical peaks corresponding to the binding energies of C1s, N1s and O1s can be observed (Fig. 8a-c), with the $\mathrm{N}$ atomic rate of 3.14 at\% (PAN: $850{ }^{\circ} \mathrm{C}$ ), 3.22 at $\%$ (PAN-Gr: $850{ }^{\circ} \mathrm{C}$ ), and 3.58 at\% (PAN@EDA@Gr: $850{ }^{\circ} \mathrm{C}$ ). Those data can confirm that the adding of $\mathrm{Gr}$ and Gr-EDA can improve the $\mathrm{N}$ content in the final samples. Such enhanced $\mathrm{N}$ content in the final samples change the surface wettability. Fig. 8A-C also demonstrate the high-resolution N1s spectra of the samples, in which the peaks can be deconvoluted into four individual peaks located at $398.28 \mathrm{eV}, 399.75 \mathrm{eV}$ and $400.94 \mathrm{eV}$, respectively, corresponding to the pyridinic $\mathrm{N}(398.2 \mathrm{eV})$, pyrrolic $\mathrm{N}(399.5$ $\mathrm{eV}$ ), quaternary $\mathrm{N}(401.1 \mathrm{eV})$ and commonly oxidized $\mathrm{N}$ (402.6 $\mathrm{eV}$, respectively. The contents of each $\mathrm{N}$ form are illustrated in

Table 2 The contents of $\mathrm{N}$ form in the final samples sinter at $850^{\circ} \mathrm{C}$

\begin{tabular}{lllll}
\hline $\begin{array}{l}\text { Samples } \\
\left(850{ }^{\circ} \mathrm{C}\right)\end{array}$ & $\begin{array}{l}\text { Pyridinic } \\
\mathrm{N}(\text { at\%) }\end{array}$ & $\begin{array}{l}\text { Pyrrolic N } \\
(\text { at\% })\end{array}$ & $\begin{array}{l}\text { Quaternary } \\
\mathrm{N}(\text { at\% })\end{array}$ & $\begin{array}{l}\text { Oxidized N } \\
(\text { at\% })\end{array}$ \\
\hline PAN & 35.2 & 19.8 & 36.6 & 8.4 \\
PAN-Gr & 35.7 & 19.7 & 35.5 & 9.1 \\
PAN-Gr-EDA & 31.0 & 14.2 & 44.0 & 10.8
\end{tabular}


Table 2. From Table 2, we can found that quaternary $\mathrm{N}$ in PAN@EDA@Gr derived DNFs is higher than those in PAN and PAN-Gr derived the CNFs and the reason is in research.

\section{Conclusion}

In summary, we have used EDA as a linker between Gr and PAN for high-performance CNFs. The improved dispersion and interaction between Gr and PAN lead to the higher carbon yield, improved Young's modulus and higher graphitic structure during the carbonization. Moreover, the EDA can act as the $\mathrm{N}$ source for N-doping during the carbonization, thus the PANGr-EDA derived CNFs also exhibited hydrophilic performance. This study provides an effective approach for development of high-strength CNFs carbonized at low temperature with significant wettability.

\section{Conflict of interest}

The authors declare no competing financial interest.

\section{Acknowledgements}

This research was supported by the Australian Research Council World Class Future Fibre Industry Transformation Research Hub (IH140100018).

\section{References}

1 M.-X. Wang, Z.-H. Huang, K. Shen, F. Kang and K. Liang, Catal. Today, 2013, 201, 109-114.

2 X. Mao, F. Simeon, G. C. Rutledge and T. A. Hatton, Adv. Mater., 2013, 25, 1309-1314.

3 G. Singh, D. Rana, T. Matsuura, S. Ramakrishna, R. M. Narbaitz and S. Tabe, Sep. Purif. Technol., 2010, 74, 202-212.

4 M. Wu, Q. Wang, X. Liu and H. Liu, Carbon, 2013, 51, 335345.

5 L. F. Zhang, A. Aboagye, A. Kelkar, C. L. Lai and H. Fong, J. Mater. Sci., 2014, 49, 463-480.

6 E. Fitzer, Carbon, 1989, 27, 621-645.

7 H. Khayyam, M. Naebe, A. Bab-Hadiashar, F. Jamshidi, Q. Li, S. Atkiss, D. Buckmaster and B. Fox, Appl. Energy, 2015, 158, 643-655.

8 R. Gupta and R. Goel, Microelectron. Reliab., 1991, 31, 1-5.

9 H. Khayyam, M. Naebe, O. Zabihi, R. Zamani, S. Atkiss and B. Fox, IEEE Transactions on Industrial Informatics, 2015, 11, 887-896.

10 M. Naebe, J. Wang, Y. Xue, X. Wang and T. Lin, J. Appl. Polym. Sci., 2010, 118, 359-365.
11 A.-T. Chien, H. C. Liu, B. A. Newcomb, C. Xiang, J. M. Tour and S. Kumar, ACS Appl. Mater. Interfaces, 2015, 7, 52815288.

12 A. K. Geim and K. S. Novoselov, Nat. Mater., 2007, 6, 183-191.

13 D. W. Li, G. H. Li, P. F. Lv, N. Ullah, C. Wang, Q. Q. Wang,

X. W. Zhang and Q. F. Wei, RSC Adv., 2015, 5, 30602-30609.

14 O. Zabihi, M. Ahmadi, M. A. Bagherjeri and M. Naebe, $R S C$ Adv. , 2015, 5, 98692-98699.

15 E. K. Lin, W.-l. Wu and S. K. Satija, Macromolecules, 1997, 30, 7224-7231.

16 S. Prilutsky, E. Zussman and Y. Cohen, Nanotechnology, 2008, 19, 165603-165612.

17 D. Papkov, A. Goponenko, O. C. Compton, Z. An, A. Moravsky, X.-Z. Li, S. T. Nguyen and Y. A. Dzenis, Adv. Funct. Mater., 2013, 23, 5763-5770.

18 A. Peera, R. K. Saini, L. B. Alemany, W. E. Billups, M. Saunders, A. Khong, M. S. Syamala and R. J. Cross, Eur. J. Org. Chem., 2003, 2003, 4140-4145.

19 X. Tang, Y. Zhao, Q. Jiao and Y. Cao, Fullerenes, Nanotubes, Carbon Nanostruct., 2010, 18, 14-23.

20 S. Wang, J. Wang, W. Zhang, J. Ji, Y. Li, G. Zhang, F. Zhang and X. Fan, Ind. Eng. Chem. Res., 2014, 53, 13205-13209.

21 H. Y. Zhang, C. Y. Xin, X. T. Wang and K. Wang, Int. J. Hydrogen Energy, 2016, 41, 12019-12028.

22 Z. Li, J. Cai, P. Cizek, H. Niu, Y. Du and T. Lin, J. Mater. Chem. A, 2015, 3, 16162-16167.

23 X. Tang, Y. Zhao, Q. Jiao and Y. Cao, Fullerenes, Nanotubes, Carbon Nanostruct., 2010, 18, 14-23.

24 S. Cetiner, H. Karakas, R. Ciobanu, M. Olariu, N. U. Kaya, C. Unsal, F. Kalaoglu and A. S. Sarac, Synth. Met., 2010, 160, 1189-1196.

25 S. Jain, J. G. P. Goossens, G. W. M. Peters, M. van Duin and P. J. Lemstra, Soft Matter, 2008, 4, 1848-1854.

26 S. Lee, J. Kim, B.-C. Ku, J. Kim and H.-I. Joh, Adv. Chem. Eng. Sci., 2012, 2, 8.

27 F. Cesano, D. Scarano, S. Bertarione, F. Bonino, A. Damin, S. Bordiga, C. Prestipino, C. Lamberti and A. Zecchina, $J$. Photochem. Photobiol., A, 2008, 196, 143-153.

28 Y. I. Jhon, C. Kim, M. Seo, W. J. Cho, S. Lee and Y. M. Jhon, Sci. Rep., 2016, 6, 2032-2039.

29 Z. Xu and C. Gao, Mater. Today, 2015, 18, 480-492.

30 D. Papkov, Y. Zou, M. N. Andalib, A. Goponenko, S. Z. D. Cheng and Y. A. Dzenis, ACS Nano, 2013, 7, 33243331.

31 G.-P. Hao, N. R. Sahraie, Q. Zhang, S. Krause, M. Oschatz, A. Bachmatiuk, P. Strasser and S. Kaskel, Chem. Commun., 2015, 51, 17285-17288. 